\title{
Deep Inspiration Breath Hold Techniques in the Radiotherapeutic Management of Left-Sided Breast Cancer-Active Breathing Coordinator vs. Voluntary Breath Hold \\ Parasuramar $\mathrm{A}^{\mathbf{1}^{*}}$, DeSmit $\mathrm{A}^{2}$ and Borg $\mathrm{M}^{2}$ \\ ${ }^{1}$ Royal Adelaide Hospital, Port Road, Adelaide SA 5000, Australia \\ ${ }^{2}$ Adelaide Radiotherapy Centre, Genesis Care, Calvary Central Districts Hospital, Jarvis Road, Elizabeth Vale, Australia
}

\section{Abstract}

Purpose: Deep Inspiration Breath Hold (DIBH) is a well-established method in reducing their radiation of the heart and lung when treating Left sided Breast cancer with EBRT. There is, however, limited literature comparing different methods of $\mathrm{DIBH}$. The purpose of our study is to compare the efficacy of Active Breathing Co-ordinator (ABC) against Voluntary Breath Hold (VBH).

Methods and Materials: 20 patients were selected whom had left sided Breast cancer and underwent EBRT. 10 patients underwent Active Breathing Coordinator (ABC) using specialized Elekta equipment and 10 performed Voluntary Breath Hold (VBH) following the JOVE protocol. All 20 patients had two CT simulation scans: one in FB and the other in DIBH. Treatment plans were generated using a tangential radiation therapy technique. A dosimetric comparison was made between the two plans as per EviQ guidelines. Measurements were collected for Lung V20 (\%), Ipsilateral Lung Maximum Depth (cm), Heart V25 (\%), Heart (Gy), and Contralateral Breast V3 (\%). 9 patients had LAD mean values measured.

Results: When using the Mann-Whitney U test to compare ABC to VBH: the VBH technique yielded a median Heart $(\mathrm{Gy})$ of $1.75(\mathrm{IQR}=1.15)$ and median Contralateral Breast V3 of $0.31 \%(\mathrm{IQR}=0.89 \%)$. The ABC technique yielded a median Heart $(\mathrm{Gy})$ of $1.44(\mathrm{IQR}=.60)$ and for the Contralateral Breast V3 a median of $0.00 \%(\mathrm{IQR}=0.00 \%)$. The $\mathrm{ABC}$ technique was statistically superior with $\mathrm{U}=15.000 \mathrm{p}=.008$ (Heart (Gy)) and $\mathrm{U}=24.500 \mathrm{p}=.035$ (Contralateral Breast V3) respectively. None of the other parameters had statistically significant median differences.

When using the Wilcoxon signed-rank test to compare DIBH to FB: The VBH technique yielded a median Ipsilateral Lung max (cm) of 2.3, Ipsilateral Lung V20 of 13.92\%, Lung V20 of 6.45\%, Heart V25 of $2.41 \%$, Heart (Gy) of 2.7, and LAD mean (Gy) of 23.4. The DIBH technique was statistically superior in these parameters and yielded a median Ipsilateral Lung $\max (\mathrm{cm})$ of $2.6(\mathrm{Z}=-3.072 \mathrm{p}=.002)$, Ipsilateral Lung V20 of $12.33 \%(Z=-2.576$ p=.01), Lung V20 of 5.84\% ( $Z=-2.296 p=.01)$, Heart V25 of $0.26 \%(Z=-$ $3.921 \mathrm{p}<.001)$, Heart (Gy) of $1.43(\mathrm{Z}=-3.921 \mathrm{p}<.001)$, and LAD mean (Gy) of $7.7(\mathrm{Z}=-2.201 \mathrm{p}=.028)$.

Conclusion: $\mathrm{ABC}$ is a superior breath hold technique when compared to $\mathrm{VBH}$ and will yield lesser long-term cardiac complications. However, it is a more expensive modality and can be poorly tolerated by patients. Surrounding structures incur significantly less radiation when using DIBH than FB which is consistent with previous studies in the literature. Further studies are required to confirm this data.

\section{Background}

Breast cancer remains the common cancer to target women in Australia [1]. Adjuvant radiotherapy (RT) has become the mainstay treatment after breast conserving surgery for invasive cancer and postmastectomy radiotherapy, boasting a reduction of local recurrence from $26 \%$ to $7 \%$ at 5 years follow-up. This same study revealed an absolute risk reduction of $5.4 \%$ in breast cancer-related mortality with radiation therapy after breast conserving surgery (BCS) compared to BCS alone [2]. As with any treatment, radiation therapy has its side-effects - multiple studies have linked left breast irradiation to increased cardiac mortality and morbidity [3-5]. Darby et al. found that the relative risk for ischaemic heart disease increased by $7.4 \%$ for every 1 Gray (Gy) increase in mean heart dose in a population base study involving 2168 patients [3].

There are many treatment techniques that have been used to minimize exposure to organs at risk (OAR) such as prone positioning, intensity-modulated radiotherapy (IMRT) and proton therapy. One of the most promising of these is the Deep Inspiration Breath Hold

\section{Publication History:}

Received: July 23, 2017

Accepted: October 10, 2017

Published: October 12, 2017

\section{Keywords:}

Female genital neoplasms, Gynecologic surgical procedures, Pelvic exenteration, Pelvic organ prolapse, Surgical mesh, Urogenital neoplasms
(DIBH). This involves the patient inspiring to a specific volume and holding their breath whilst receiving radiotherapy which displaces the heart and subsequently reducing the radiation it incurs. This technique has been widely recognized as an effective means of reducing radiation exposure to the heart without compromising the therapeutic dose to breast cancer tissue [6-15].

There are several different breath-hold techniques that have been utilized all over the world. One of the most common methods is via

"Corresponding Author: Dr. Amaran Parasuramar, Royal Adelaide Hospital, Port Road, Adelaide SA 5000, Australia, Tel: 0403368483; E-mail: amaran.parasuramar@gmail.com

Citation: Parasuramar A, DeSmit A, Borg M (2017) Deep Inspiration Breath Hold Techniques in the Radiotherapeutic Management of Left-Sided Breast CancerActive Breathing Coordinator vs. Voluntary Breath Hold. Int J Gynecol Clin Pract 4: 133. doi: https://doi.org/10.15344/2394-4986/2017/133

Copyright: @ 2017 Parasuramar et al. This is an open-access article distributed under the terms of the Creative Commons Attribution License, which permits unrestricted use, distribution, and reproduction in any medium, provided the original author and source are credited. 
Citation: Parasuramar A, DeSmit A, Borg M (2017) Deep Inspiration Breath Hold Techniques in the Radiotherapeutic Management of Left-Sided Breast CancerActive Breathing Coordinator vs. Voluntary Breath Hold. Int J Gynecol Clin Pract 4: 133. doi: https://doi.org/10.15344/2394-4986/2017/133

the spirometry-based Active Breathing Coordinator (ABC) system made by Elekta (Stockholm, Sweden). This device is a mouthpiece attached to a spirometer, the patient's nose is pegged to prevent nasal respiration. The radiotherapist (staff member who runs the linear accelerator) is then able to monitor the patient's inspiration volume and when it has reached a predetermined threshold pinch-valves activate to prevent the patient from exhaling or inhaling and the radiation dose is administered. This technique has been proven to be an effective method for DIBH [16-33].

One of the difficulties with this system is its cost, not only in the machine itself but with new mouthpieces and specialized training for staff. For some years this prevented widespread implementation of the Breath Hold Technique. The Voluntary Breath Hold was then conceived as a simple and inexpensive alternative to the $\mathrm{ABC}$ DIBH. The protocol that Bartlett et al. developed was the method we implemented in our study for VBH. There is considerable data comparing DIBH against free breathing radiotherapy in left sided breast cancer however there are limited trails comparing the efficacy of varying DIBH techniques. Bartlett et al. compared $\mathrm{ABC}$ assisted DIBH and voluntary DIBH in terms of setup reproducibility, normal tissue sparing and feasibility of delivery. Our study looks to further compare the efficacy of two different techniques of DIBH investigated in our centre - Active breathing coordinator (Elekta) and Voluntary breath hold with dosimetric endpoints.

\section{Methods and Materials}

Selection criteria involved women who were 70 years old or less, of performance status 0 or 1 , with left sided breast cancer. Patients with poor function were excluded. They had to be fluent in English, had no hearing impairments and must be able to fit through the planning CT scan (size dependent). Patients had to be able to undergo device training and hold their breath at $50 \%$ greater capacity than their resting lung volume. 20 patients in total were selected, 10 assigned to $\mathrm{ABC}$ and 10 assigned to $\mathrm{VBH}$.

Of the $\mathrm{ABC}$ cohort patients were able to receive adjuvant left breast or chest wall irradiation, and where indicated, supraclavicular, axillary, or internal mammary nodal (IMC) irradiation. VBH patients were only able to receive left breast orchest wall radiotherapy as we were unable to ensure an accurate setup in those patients that were recommended nodal irradiation.

Two comparable techniques were introduced - active breathing coordinator (using specialised Elekta equipment) and voluntary breath hold (without equipment following the Bartlett et al. protocol). All twenty patients underwent two CT simulation scans one in 'Free Breathing (FB)' and the other in 'Breath-Hold' (ABC or VBH). Treatment plans were generated using a tangential radiation therapy technique. A dosimetric comparison was made between the two plans for the heart, left lung and contralateral breast as per EviQ guidelines [34,35]. Measurements were collected for Lung V20 (\%), Ipsilateral Lung Maximum Depth (cm), Heart V25 (\%), Heart (Gy), and Contralateral Breast V3 (\%). 9 patients had LAD mean values measured. Comparison was made, firstly, for FB against DIBH and then for $\mathrm{ABC}$ against $\mathrm{VBH}$.

The Bartlett et al. protocol involved using the distance moved by anterior and lateral reference tattoos away from the treatment room lasers whilst in breath-hold. This allowed staff to monitor the consistency between the CT-planning stage and the treatment setup stage [36].
Patient suitability was first assessed with the aforementioned criteria. They were then asked to practice holding their breath at home whilst lying down, initially for 5 seconds building up to 20 seconds. During the planning CT scan stage, tattoos and CT markers were placed on the patient's midline in free breathing and approximately half way along the likely field edges. Then lateral markers were added to the patients in free-breathing. The maximum duration for which the patients can hold their breath was measured. The position of the anterior and lateral tattoos was marked in relation to the lasers in breath-hold to help establish reproducibility. The light fields were measured and marked in the medial and lateral borders whilst in free-breathing and breath-hold. The field borders were marked on the skin to help with reproducibility. When administering radiotherapy the patient was instructed to breath hold and treatment was delivered when the light fields aligned satisfactorily with the marked field border. Twenty consecutive patients were offered and agreed to participate. They were randomly selected to either of the 2 study arms.

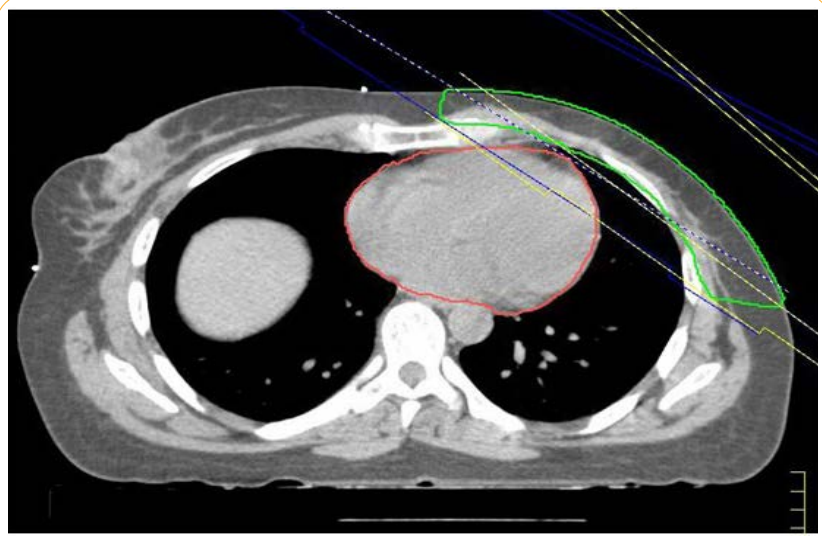

Figure 1: Planning CT scan indicating the area irradiated in Free Breathing.

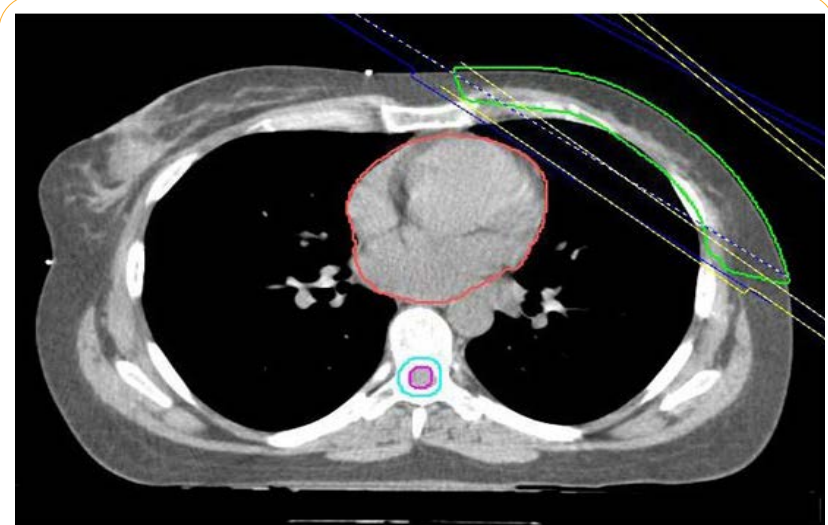

Figure 2: Planning CT scan indicating the area irradiated in DIBH (ABC).

Radiation related clinical characteristics data were collected from a total of 20 patients $(\mathrm{N}=20)$. The clinical characteristics were recorded for all 20 patients after subjecting them to one of the DIBH techniques $(\mathrm{ABC}$ or $\mathrm{VBH})$ in addition to Free breathing. Out of the 20 patients who were subjected to $\mathrm{DIBH}, 10$ patients each were assigned to both the $\mathrm{ABC}$ and $\mathrm{VBH}$ techniques.

The Wilcoxon signed-rank test is a non-parametric statistical hypothesis test used when comparing two related samples. This test was used to compare the median values of the patient's clinical characteristics for DIBH and Free breathing as both the techniques were used on the same set of patients. 
Citation: Parasuramar A, DeSmit A, Borg M (2017) Deep Inspiration Breath Hold Techniques in the Radiotherapeutic Management of Left-Sided Breast CancerActive Breathing Coordinator vs. Voluntary Breath Hold. Int J Gynecol Clin Pract 4: 133. doi: https://doi.org/10.15344/2394-4986/2017/133

Page 3 of 7

The Mann-Whitney $\mathrm{U}$ test was used to compare the patient's median values of the clinical characteristics for the $\mathrm{ABC}$ and the VBH techniques as both the techniques were used on a different set of patients. Only the statistically significant results have been reported.

Clinical characteristics have been described using summary statistics (mean and standard deviation (SD) or median and interquartile range (IQR)) depending on the distribution of the variable.

\section{Results}

The results from the Shapiro-Wilk test of normality are summarised in tables 1 and table 2. These indicate that a substantial number of variables listed in table 1 and table 2 cannot be assumed to be from a normally distributed population (as the p-value of the Shapiro-Wilk statistic is less than .001). Therefore, subsequently, non-parametric statistics (i.e. Medians and Inter-quartile range) and techniques (e.g. Mann-Whitney U test) have been used to address the aims of the data analysis.

\begin{tabular}{|l|l|l|l|}
\hline \multirow{2}{*}{ Characteristic } & \multicolumn{3}{|c|}{ Shapiro-Wilk } \\
\cline { 2 - 4 } & Statistic & Df & Sig. \\
\hline DIBH Ipsilat Lung max $(\mathrm{cm})$ & .711 & 20 & $<.001$ \\
\hline DIBH Ipsilat Lung V20 & .853 & 20 & .003 \\
\hline DIBH lung V20 & 0791 & 20 & .001 \\
\hline DIBH Heart V25 & .831 & 20 & .003 \\
\hline DIBH Heart (Gy) & .880 & 20 & .018 \\
\hline DIBH Contralat Breast V3 & .420 & 20 & $<.001$ \\
\hline DIBH LAD mean (Gy) & .911 & 9 & .325 \\
\hline Free Breathing Ipsilat Lung max (cm) & .778 & 20 & $<.001$ \\
\hline Free Breathing Ipsilat Lung V20 & .252 & 20 & $<.001$ \\
\hline Free Breathing Lung V20 & .850 & 20 & .005 \\
\hline Free Breathing Heart V25 & .886 & 20 & .023 \\
\hline Free Breathing Heart Mean (Gy) & .898 & 20 & .038 \\
\hline Free Breathing Contralat Breast V3 & .415 & 20 & $<.001$ \\
\hline Free Breathing LAD Mean (Gy) & .883 & 7 & .238 \\
\hline
\end{tabular}

Table 1: Test of normality-DIBH vs. free breathing group variables.
The summary statistics for the clinical characteristics of the patients for the DIBH and Free breathing techniques, and results from the Wilcoxon signed-rank test are shown in Table 3 below. The Wilcoxon test found that: the median Ipsilateral Lung maximum $(\mathrm{cm})$ with the $\mathrm{DIBH}$ technique (Median $=2.6, \mathrm{IQR}=.58)$ was significantly more $(\mathrm{Z}=-$ $3.072, \mathrm{p}=.002)$ than that of the Free breathing technique (Median $=2.3$, $\mathrm{IQR}=.78$ ); the median Ipsilateral Lung V20 (the percentage of the lung volume which receives radiation doses of $20 \mathrm{~Gy}$ or more) with the DIBH technique (Median $=12.33 \%, \mathrm{IQR}=4.24 \%$ ) was significantly less $(\mathrm{Z}=-2.576, \mathrm{p}=.01)$ than that of the $\mathrm{FB}$ technique (Median $=13.92 \%$, $\mathrm{IQR}=11.03 \%$ ); the median Lung V20 with the DIBH technique (Median $=5.84 \%, \mathrm{IQR}=1.34 \%)$ was significantly less $(\mathrm{Z}=-2.296$, $\mathrm{p}=.022$ ) than that of the FB technique (Median $=6.45 \%, \mathrm{IQR}=3.56 \%$ ); the median Heart V25 (the percentage of the heart volume which receives radiation doses of $25 \mathrm{~Gy}$ or more) with the DIBH technique (Median $=.26 \%, \mathrm{IQR}=.46 \%)$ was significantly less $(\mathrm{Z}=-3.921, \mathrm{p}<.001)$ than that of the FB technique (Median $=2.41 \%, \mathrm{IQR}=2.86 \%$ ); the median Heart (Gy) with the DIBH technique (Median=1.43, $\mathrm{IQR}=.68)$ was significantly less $(\mathrm{Z}=-3.921, \mathrm{p}<.001)$ than that of the FB technique (Median=2.7, IQR=1.78); and the median LAD mean (Left anterior descending artery measured in Gy) with the DIBH technique

\begin{tabular}{|l|c|c|c|c|}
\hline \multirow{2}{*}{ Characteristic } & \multicolumn{4}{|c|}{ Shapiro-Wilk } \\
\cline { 2 - 5 } & Sub-group & Statistic & df & Statistic \\
\hline DIBH Ipsilat Lung max & ABC & .892 & 10 & .197 \\
$(\mathrm{~cm})$ & VBH & .654 & 10 & $<.001$ \\
\hline DIBH Ipsilat Lung V20 & ABC & .947 & 10 & .635 \\
& VBH & .612 & 10 & $<.001$ \\
\hline DIBH lung V20 & ABC & .953 & 10 & .699 \\
& VBH & .624 & 10 & $<.001$ \\
\hline DIBH Heart V25 & ABC & .784 & 10 & .009 \\
& VBH & .916 & 10 & .328 \\
\hline DIBH Heart (Gy) & ABC & .906 & 10 & .253 \\
& VBH & .895 & 10 & .194 \\
\hline DIBH Contralat Breast V3 & ABC & .366 & 10 & $<.001$ \\
& VBH & .477 & 10 & $<.001$ \\
\hline DIBH LAD mean (Gy) & ABC & .750 & 10 & $<.001$ \\
& VBH & .893 & 10 & .335 \\
\hline
\end{tabular}

Table 1: Test of normality-DIBH by sub-group variables.

\begin{tabular}{|c|c|c|c|c|c|c|c|c|c|c|c|}
\hline \multirow[t]{2}{*}{ Characteristic } & \multicolumn{10}{|c|}{ Percentiles } & \multirow[b]{2}{*}{ sig. } \\
\hline & $\mathrm{N}$ & Mean & SD & Min & Max. & $25^{\text {th }}$ & $50^{\text {th }}($ Median $)$ & $75^{\text {th }}$ & IQR & Z & \\
\hline $\begin{array}{l}\text { DIBH Ipsilat Lung } \max (\mathrm{cm}) \\
\text { Free Breathing Ipsilat Lung } \max (\mathrm{cm})\end{array}$ & $\begin{array}{l}20 \\
20\end{array}$ & $\begin{array}{l}2.74 \\
2.46\end{array}$ & $\begin{array}{l}0.88 \\
0.79\end{array}$ & $\begin{array}{l}1.40 \\
1.70\end{array}$ & $\begin{array}{l}6.00 \\
5.20\end{array}$ & $\begin{array}{l}2.40 \\
1.93\end{array}$ & $\begin{array}{l}2.60 \\
2.30\end{array}$ & $\begin{array}{l}2.98 \\
2.70\end{array}$ & $\begin{array}{l}0.58 \\
0.78\end{array}$ & -3.072 & .002 \\
\hline $\begin{array}{l}\text { DIBH Ipsilat Lung V20 } \\
\text { Free Breathing Ipsilat Lung V20 }\end{array}$ & $\begin{array}{l}20 \\
20\end{array}$ & $\begin{array}{l}13.54 \% \\
88.78 \%\end{array}$ & $\begin{array}{c}5.01 \% \\
325.42 \%\end{array}$ & $\begin{array}{l}6.17 \% \\
8.05 \%\end{array}$ & $\begin{array}{c}30.04 \% \\
1471.00 \%\end{array}$ & $\begin{array}{l}10.97 \% \\
11.38 \%\end{array}$ & $\begin{array}{l}12.33 \% \\
13.92 \%\end{array}$ & $\begin{array}{l}15.20 \% \\
22.40 \%\end{array}$ & $\begin{array}{c}4.24 \% \\
11.03 \%\end{array}$ & -2.576 & .010 \\
\hline $\begin{array}{l}\text { DIBH lung V20 } \\
\text { Free Breathing Lung V20 }\end{array}$ & $\begin{array}{l}20 \\
20\end{array}$ & $\begin{array}{l}6.24 \% \\
7.26 \%\end{array}$ & $\begin{array}{l}2.32 \% \\
3.26 \%\end{array}$ & $\begin{array}{l}2.82 \% \\
3.35 \% \\
\end{array}$ & $\begin{array}{l}14.24 \% \\
17.58 \% \\
\end{array}$ & $\begin{array}{l}5.17 \% \\
4.92 \%\end{array}$ & $\begin{array}{l}5.84 \% \\
6.45 \% \\
\end{array}$ & $\begin{array}{l}6.51 \% \\
8.48 \%\end{array}$ & $\begin{array}{l}1.34 \% \\
3.56 \%\end{array}$ & -2.296 & .022 \\
\hline $\begin{array}{l}\text { DIBH Heart V25 } \\
\text { Free Breathing Heart V25 }\end{array}$ & $\begin{array}{l}20 \\
20\end{array}$ & $\begin{array}{l}0.31 \% \\
2.90 \%\end{array}$ & $\begin{array}{l}0.31 \% \\
1.96 \%\end{array}$ & $\begin{array}{l}0.00 \% \\
0.83 \%\end{array}$ & $\begin{array}{l}1.30 \% \\
7.32 \%\end{array}$ & $\begin{array}{l}0.05 \% \\
1.25 \%\end{array}$ & $\begin{array}{l}0.26 \% \\
2.41 \%\end{array}$ & $\begin{array}{l}0.50 \% \\
4.10 \%\end{array}$ & $\begin{array}{l}0.46 \% \\
2.86 \%\end{array}$ & -3.921 & $<.001$ \\
\hline $\begin{array}{l}\text { DIBH Heart (Gy) } \\
\text { Free Breathing Heart Mean (Gy) }\end{array}$ & $\begin{array}{l}20 \\
20\end{array}$ & $\begin{array}{l}1.55 \\
2.92\end{array}$ & $\begin{array}{l}0.63 \\
1.22\end{array}$ & $\begin{array}{l}0.82 \\
1.40\end{array}$ & $\begin{array}{l}3.00 \\
5.10\end{array}$ & $\begin{array}{l}1.10 \\
1.90\end{array}$ & $\begin{array}{l}1.43 \\
2.70\end{array}$ & $\begin{array}{l}1.78 \\
3.68\end{array}$ & $\begin{array}{l}0.68 \\
1.78\end{array}$ & -3.921 & $<.001$ \\
\hline $\begin{array}{l}\text { DIBH Contralat Breast V3 } \\
\text { Free Breathing Contralat Breast V3 }\end{array}$ & $\begin{array}{l}20 \\
20\end{array}$ & $\begin{array}{l}1.29 \% \\
2.13 \%\end{array}$ & $\begin{array}{l}3.49 \% \\
6.07 \%\end{array}$ & $\begin{array}{l}0.00 \% \\
0.00 \%\end{array}$ & $\begin{array}{l}12.72 \% \\
25.67 \%\end{array}$ & $\begin{array}{l}0.00 \% \\
0.00 \%\end{array}$ & $\begin{array}{l}0.00 \% \\
0.00 \%\end{array}$ & $\begin{array}{l}0.47 \% \\
0.36 \%\end{array}$ & $\begin{array}{l}0.47 \% \\
0.36 \%\end{array}$ & -0.711 & .477 \\
\hline $\begin{array}{l}\text { DIBH LAD mean (Gy) } \\
\text { Free Breathing LAD Mean (Gy) }\end{array}$ & $\begin{array}{l}9 \\
7\end{array}$ & $\begin{array}{c}6.85 \\
20.87\end{array}$ & $\begin{array}{l}3.43 \\
7.21\end{array}$ & $\begin{array}{l}2.50 \\
6.90\end{array}$ & $\begin{array}{l}11.80 \\
27.80\end{array}$ & $\begin{array}{c}3.65 \\
16.90\end{array}$ & $\begin{array}{c}7.70 \\
23.40\end{array}$ & $\begin{array}{c}9.83 \\
26.60\end{array}$ & $\begin{array}{l}6.18 \\
9.70\end{array}$ & -2.201 & .028 \\
\hline
\end{tabular}

Table 3: DIBH vs. free breating techniques 
Citation: Parasuramar A, DeSmit A, Borg M (2017) Deep Inspiration Breath Hold Techniques in the Radiotherapeutic Management of Left-Sided Breast CancerActive Breathing Coordinator vs. Voluntary Breath Hold. Int J Gynecol Clin Pract 4: 133. doi: https://doi.org/10.15344/2394-4986/2017/133

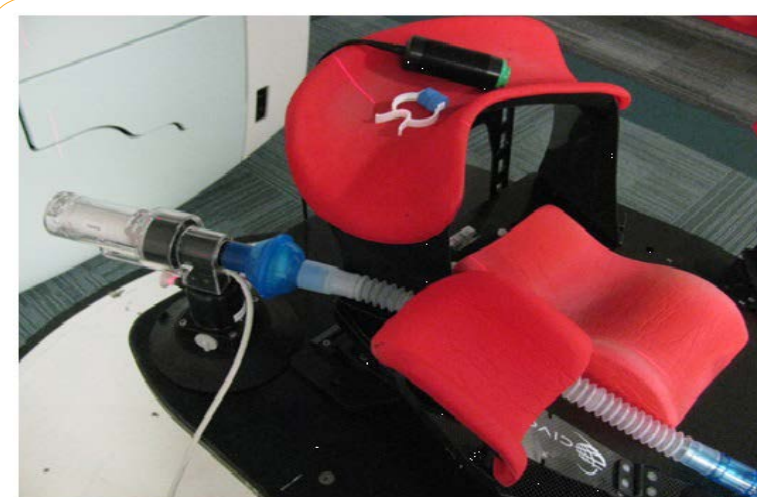

Figure 3: The Active Breathing Coordinator (Elekta@) set up at Adelaide Radiotherapy Centre.

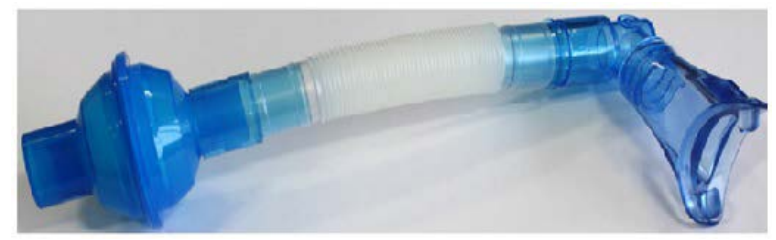

Figure 4: The Active Breathing Coordinator mouth piece.

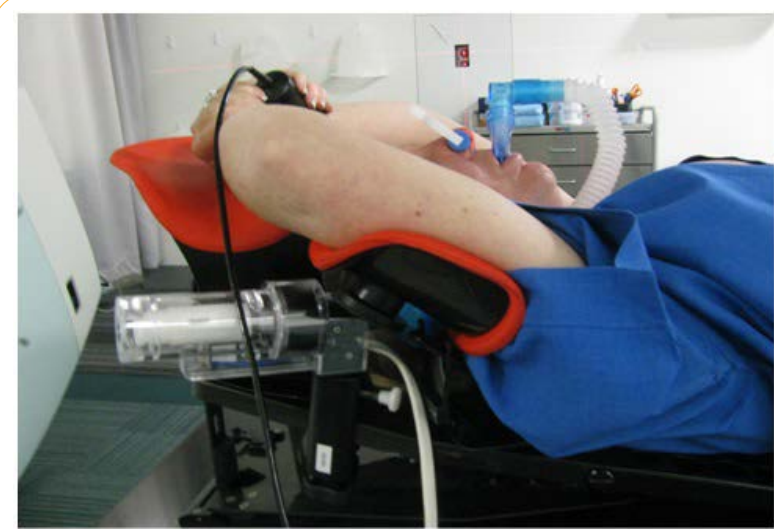

Figure 5: A patient using the $\mathrm{ABC}$ deep inspiration breath hold.

(Median=7.7, IQR=6.18) was significantly less $(\mathrm{Z}=-2.201, \mathrm{p}=.028)$ than that of the FB technique (Median=23.4, IQR=9.7). There was no statistically significant difference between the median Contralateral Breast V3 (the percentage of the contralateral breast volume which receives radiation doses of $3 \mathrm{~Gy}$ or more) values of the $\mathrm{DIBH}$ and $\mathrm{FB}$ technique groups.

The summary statistics for the clinical characteristics of the patients for the $\mathrm{ABC}$ and $\mathrm{VBH}$, and results from the Mann-Whitney $\mathrm{U}$ test are shown in Table 4 below. The Mann-Whitney $U$ test found that: the median Heart (Gy) with the ABC technique (Median=1.44, IQR=.60) was significantly less $(\mathrm{U}=15.000, \mathrm{p}=.008)$ than that of the $\mathrm{VBH}$ technique (Median=1.75, IQR=1.15); and the median Contralateral Breast V3 with the $\mathrm{ABC}$ technique (Median $=0.00 \%$, IQR $=0.00 \%$ ) was significantly less $(\mathrm{U}=24.500, \mathrm{p}=.035)$ than that of the $\mathrm{VBH}$ technique (Median $=0.31 \%, \mathrm{IQR}=0.89 \%$ ). None of the other differences between the median values for the clinical characteristics were significantly different between the $\mathrm{ABC}$ and $\mathrm{VBH}$ technique groups.

\section{Data Analysis Summary}

The results of the data analysis indicated that the Ipsilateral Lung maximum $(\mathrm{cm})$ is significantly higher for the DIBH group implying DIBH to be a better technique compared to Free Breathing. This assertion is further supported by the following clinical characteristics being significantly lower for the Free breathing technique group: Ipsitlateral Lung V20, Lung V20, Heart V25, Heart (Gy), and LAD mean (Gy).

Additionally, the results of the data analysis indicated that the Heart (Gy) and the Contralateral Breast V3 (\%) values were significantly higher for the $\mathrm{VBH}$ technique group compared to the $\mathrm{ABC}$ technique group. This indicates that $\mathrm{ABC}$ is a more effective technique compared to $\mathrm{VBH}$ as far as these clinical characteristics are concerned.

\section{Discussion}

Multiple population based studies have demonstrated the increased risk in cardiac mortality in patients who undergo left sided breast cancer radiotherapy [5,37-39]. The most recent Early Breast Cancer Trailists' Collaborative Group meta-analyses showed that adjuvant RT

\begin{tabular}{|c|c|c|c|c|c|c|c|c|c|c|c|c|c|}
\hline \multirow[t]{2}{*}{ Characteristic } & \multicolumn{12}{|c|}{ Percentiles } & \multirow[b]{2}{*}{ sig. } \\
\hline & Sub-Group & $\mathrm{N}$ & Missing & Mean & Min. & SD & Max. & $25^{\text {th }}$ & $\begin{array}{c}50^{\text {th }} \\
\text { (Median) }\end{array}$ & $75^{\text {th }}$ & IQR & $\mathrm{Z}$ & \\
\hline DIBH Ipsilat Lung max $(\mathrm{cm})$ & $\begin{array}{l}\mathrm{ABC} \\
\mathrm{VBH}\end{array}$ & $\begin{array}{l}10 \\
10\end{array}$ & $\begin{array}{l}0 \\
0\end{array}$ & $\begin{array}{l}2.35 \\
2.95\end{array}$ & $\begin{array}{l}1.40 \\
2.00\end{array}$ & $\begin{array}{l}0.53 \\
1.12\end{array}$ & $\begin{array}{l}3.10 \\
6.00\end{array}$ & $\begin{array}{l}2.10 \\
2.40\end{array}$ & $\begin{array}{l}2.70 \\
2.55\end{array}$ & $\begin{array}{l}2.93 \\
3.10\end{array}$ & $\begin{array}{l}0.83 \\
0.70\end{array}$ & 45.000 & .704 \\
\hline DIBH Ipsilat Lung V20 & $\begin{array}{l}\mathrm{ABC} \\
\mathrm{VBH}\end{array}$ & $\begin{array}{l}10 \\
10\end{array}$ & $\begin{array}{l}0 \\
0\end{array}$ & $\begin{array}{l}13.80 \% \\
13.27 \%\end{array}$ & $\begin{array}{l}6.17 \% \\
8.80 \%\end{array}$ & $\begin{array}{l}3.96 \% \\
6.09 \%\end{array}$ & $\begin{array}{l}19.05 \% \\
30.04 \%\end{array}$ & $\begin{array}{l}11.18 \% \\
10.09 \%\end{array}$ & $\begin{array}{l}14.50 \% \\
11.98 \%\end{array}$ & $\begin{array}{l}16.67 \% \\
12.90 \%\end{array}$ & $\begin{array}{l}5.50 \% \\
2.81 \%\end{array}$ & 36.000 & .290 \\
\hline DIBH lung V20 & $\begin{array}{l}\mathrm{ABC} \\
\mathrm{VBH}\end{array}$ & $\begin{array}{l}10 \\
10\end{array}$ & $\begin{array}{l}0 \\
0\end{array}$ & $\begin{array}{l}6.22 \% \\
6.25 \%\end{array}$ & $\begin{array}{l}2.82 \% \\
4.00 \%\end{array}$ & $\begin{array}{l}1.69 \% \\
2.91 \%\end{array}$ & $\begin{array}{c}9.71 \% \\
14.24 \%\end{array}$ & $\begin{array}{l}5.33 \% \\
4.66 \%\end{array}$ & $\begin{array}{l}6.22 \% \\
5.69 \%\end{array}$ & $\begin{array}{l}7.50 \% \\
6.12 \%\end{array}$ & $\begin{array}{l}2.17 \% \\
1.47 \%\end{array}$ & 36.000 & .290 \\
\hline DIBH Heart V25 & $\begin{array}{l}\mathrm{ABC} \\
\mathrm{VBH}\end{array}$ & $\begin{array}{l}10 \\
10\end{array}$ & $\begin{array}{l}0 \\
0\end{array}$ & $\begin{array}{l}0.31 \% \\
0.32 \%\end{array}$ & $\begin{array}{l}0.00 \% \\
0.00 \%\end{array}$ & $\begin{array}{l}0.40 \% \\
0.19 \%\end{array}$ & $\begin{array}{l}1.30 \% \\
0.54 \%\end{array}$ & $\begin{array}{l}0.01 \% \\
0.20 \%\end{array}$ & $\begin{array}{l}0.21 \% \\
0.29 \%\end{array}$ & $\begin{array}{l}0.51 \% \\
0.52 \%\end{array}$ & $\begin{array}{l}0.50 \% \\
0.32 \%\end{array}$ & 40.000 & .449 \\
\hline DIBH Heart (Gy) & $\begin{array}{l}\mathrm{ABC} \\
\mathrm{VBH}\end{array}$ & $\begin{array}{l}10 \\
10\end{array}$ & $\begin{array}{l}0 \\
0\end{array}$ & $\begin{array}{l}1.18 \\
1.91\end{array}$ & $\begin{array}{l}0.82 \\
1.10\end{array}$ & $\begin{array}{l}0.33 \\
0.66\end{array}$ & $\begin{array}{l}1.70 \\
3.00\end{array}$ & $\begin{array}{l}0.84 \% \\
1.43 \%\end{array}$ & $\begin{array}{l}1.17 \\
1.75\end{array}$ & $\begin{array}{l}1.44 \\
2.57\end{array}$ & $\begin{array}{l}0.60 \\
1.15\end{array}$ & 15.000 & .008 \\
\hline DIBH Contralat Breast V3 & $\begin{array}{l}\mathrm{ABC} \\
\mathrm{VBH}\end{array}$ & $\begin{array}{l}10 \\
10\end{array}$ & $\begin{array}{l}0 \\
0\end{array}$ & $\begin{array}{l}1.00 \% \\
1.58 \% \\
\end{array}$ & $\begin{array}{l}0.00 \% \\
0.00 \%\end{array}$ & $\begin{array}{l}3.16 \% \\
3.93 \%\end{array}$ & $\begin{array}{l}10.00 \% \\
12.72 \%\end{array}$ & $\begin{array}{l}0.00 \% \\
0.00 \%\end{array}$ & $\begin{array}{l}0.00 \% \\
0.31 \% \\
\end{array}$ & $\begin{array}{l}0.00 \% \\
0.89 \%\end{array}$ & $\begin{array}{l}0.00 \% \\
0.89 \%\end{array}$ & 24.500 & .035 \\
\hline DIBH LAD mean (Gy) & $\begin{array}{l}\mathrm{ABC} \\
\mathrm{VBH}\end{array}$ & $\begin{array}{l}3 \\
6\end{array}$ & $\begin{array}{l}0 \\
0\end{array}$ & $\begin{array}{l}6.20 \\
7.18\end{array}$ & $\begin{array}{l}3.20 \\
2.50\end{array}$ & $\begin{array}{l}2.60 \\
3.96\end{array}$ & $\begin{array}{c}7.70 \\
11.80\end{array}$ & $\begin{array}{l}3.20 \\
3.70\end{array}$ & $\begin{array}{l}7.70 \\
6.48\end{array}$ & $\begin{array}{c}- \\
11.73\end{array}$ & $\begin{array}{c}- \\
8.03\end{array}$ & 7.000 & .604 \\
\hline
\end{tabular}

Table 4: ABC vs. VBH techniques 
Citation: Parasuramar A, DeSmit A, Borg M (2017) Deep Inspiration Breath Hold Techniques in the Radiotherapeutic Management of Left-Sided Breast CancerActive Breathing Coordinator vs. Voluntary Breath Hold. Int J Gynecol Clin Pract 4: 133. doi: https://doi.org/10.15344/2394-4986/2017/133

Page 5 of 7

after BCS reduces the rate of breath cancer mortality compared to surgery alone $[40,41]$. The significant reduction in breast cancer mortality that has been cited appear to diminish over time due to cardiotoxicity related to radiotherapy exposure. This has historically been difficult to assess since cardiac and pulmonary toxicities associated with radiotherapy are late-stage effects and lag decades after treatment has occurred. These results would not take into account the benefits accrued from modern radiotherapeutic techniques but also the deleterious effects of cardiac toxicity from chemotherapy [42]. This has led to the development of techniques to help reduce the radiation doses toadjacent organs-at-risk - including the deep inspiration breath hold.

Our study's primary aim was to compare the efficacy of Active Breathing Coordinator (ABC) against Voluntary Breath Hold (VBH). There is minimal data present in the literature that compares these two techniques. Bartlett et al. studied 23 patients, who completed both $\mathrm{VBH}$ and $\mathrm{ABC}$, and used Electronic Portal Imaging (EPI) values to determine positional reproducibility. They also measured heart, leftanterior descending coronary artery and lung doses and found that there was no statistical difference present. They found that VBH was preferred by patients and radiographers, takes less time to deliver and is cheaper than $\mathrm{ABC}$ [43]. The authors of this study also conceived the protocol that we used for our $\mathrm{VBH}$.

We studied 20 patients who underwent both FB and DIBH. These patients were split randomly into 2 groups, 10 undertaking the $A B C$ technique and 10 undertaking the $\mathrm{VBH}$ technique. Our data revealed similar results when comparing the efficacy of DIBH in reducing radiation doses to organs-at-risk against free breathing. There was, however, a statistically significant difference between the Heart (Gy) and Contralateral Breast V3 (\%) between ABC and VBH. This showed that $\mathrm{ABC}$ was a more effective breath hold technique than $\mathrm{VBH}$.

$\mathrm{ABC}$ is a more expensive technique when accounting for the equipment and the need to use a new mouthpiece for each patient Specialized training is also required for radiotherapists to use the machinery and software. Patients must be able to follow commands and understand the concepts involved. This technique also has patient dependent limitations including claustrophobia and poor lung function. In contrast $\mathrm{VBH}$ is a simpler and cheaper technique to implement and is better tolerated by patients. In our cohort patients tolerated $\mathrm{ABC}$ DIBH very well and had no issues with compliance.

Our study's results suggest that DIBH should be implemented as routine clinical practice for left sided breast cancer patients receiving radiotherapy as there is a clinically relevant dose reduction to cardiac structures. In addition to this $\mathrm{ABC}$ has been shown to be a superior breath hold technique and should be the technique of choice for DIBH. We found that using ABC was a more efficient approach once staff were trained adequately, the time taken per fraction was approximately 18 minutes compared to 25 minutes for $\mathrm{VBH}$.

Deep Inspiration Breath Hold Technique reduces ipsilateral lung dose via inflation causing less tissue to remain in the irradiated region. It has been previously shown that the use of deep inspiration breath hold technique in breast cancer patients can reduce the mean lung dose by $15 \%$ and the Lung V20 by $17 \%$, when compare to free breathing techniques [44].

Limitations to this study were population size and the single-centre nature of the study. Also at the time of writing this article measurements of LAD doses had not been determined in all 20 patients. The implications of potentially cardiotoxic chemotherapy can confound the data and was not considered in our study. Given that this was a dosimetric study, cardiac morbidity and survival were not evaluated. Clinical correlation with cardiac dose-volume parameters is required in the future to accurately predict the dose needed to reduce cardiac morbidity and mortality. It was demonstrated by Darby et al. that the rate of coronary event increases by $7.4 \%$ for every 1 Gy irradiated to the heart $[4,45]$.

There has been an impetus to measure radiotherapy related cardiotoxicity using Single Photon Emission Computer Tomography (SPECT) scans which allows us to detect adverse changes earlier. Prosnitz et al. demonstrated in one study that patients receiving left sided adjuvant radiation for breast cancer had detectable SPECT scan changes evident 3 to 6 years post-radiation therapy [46]. Most other cardiotoxic effects develop several yearsafter the initial radiotherapy. In the future this may be an option for more accurate measurements of irradiation of innocent structures.

Mittauer et al. showed that an Optical tracking system can be a valuable tool for real-time quality control of ABC-assisted DIBH [47]. This method will help increase precision and reproducibility of DIBH in turn reducing the irradiation of the heart.

Further studies are required to confirmthis data including larger study populations with varying co-morbidities and body habitus. Comparison of other breath-hold methods will help practitioners to select appropriate treatments amongst the myriad of options. Long term follow-up is required to fully determine the clinical outcomes associated with irradiation to the heart and lung. Additionally, further research should help develop more stringent patient-selection criteria. These studies should also target patient coaching and treatment verification protocols which will improve the efficiency and reproducibility of the technique.

\section{Conclusion}

In our study consisting of 20 patients undergoing left sided breast cancer radiotherapy we showed that DIBH was a superior means of administering radiotherapy than free breathing. In addition to this we demonstrated that $\mathrm{ABC}$ was a superior breath hold technique when compared to VBH. Future studies are required to confirm our findings.

\section{Competing Interests}

The authors declare that they have no competing interests.

\section{References}

1. AlHW \& AACR (2012) Cancer in Australia: an overview, Cancer Ser no74 2012; Cat. no. C: Canberra: AlHW.

2. Early Breast Cancer Trialists' Collaborative Group (1995) Effects of radiotherapy and surgery in early breast cancer. An overview of the randomized trials. Early Breast Cancer Trialists' Collaborative Group. N Engl J Med 333: 1444-1455

3. Darby SC, McGale P, Taylor CW, Peto R (2005) Long-term mortality from heart disease and lung cancer after radiotherapy for early breast cancer: prospective cohort study of about 300,000 women in US SEER cancer registries. Lancet Oncol 6: 557-565.

4. Darby SC, Ewertz M, McGale P, Bennet AM, Blom-Goldman U, et al. (2013) Risk of ischemic heart disease in women after radiotherapy for breast cancer. N Engl J Med 368: 987-998. 
Citation: Parasuramar A, DeSmit A, Borg M (2017) Deep Inspiration Breath Hold Techniques in the Radiotherapeutic Management of Left-Sided Breast CancerActive Breathing Coordinator vs. Voluntary Breath Hold. Int J Gynecol Clin Pract 4: 133. doi: https://doi.org/10.15344/2394-4986/2017/133

Page 6 of 7

5. Rutqvist LE, Johansson H (1990) Mortality by laterality of the primary tumour among 55,000 breast cancer patients from the Swedish Cance Registry. Br J Cancer 61: 866-868.

6. Lu HM, Cash E, Chen MH, Chin L, Manning WJ, Harris J, et al. (2000) Reduction of cardiac volume in left-breast treatment fields by respiratory maneuvers: a CT study. Int J Radiat Oncol Biol Phys 47: 895-904.

7. Sixel KE, Aznar MC, Ung YC (2001) Deep inspiration breath hold to reduce irradiated heart volume in breast cancer patients. Int J Radiat Oncol Biol Phys 49: 199-204.

8. Remouchamps VM, Letts N, Vicini FA, Sharpe MB, Kestin LL, et al. (2003) Initial clinical experience with moderate deep-inspiration breath hold using an active breathing control device in the treatment of patients with left-sided breast cancer using external beam radiation therapy. Int J Radiat Oncol Biol Phys 56: 704-715.

9. Pedersen AN, Korreman S, Nyström H, Specht L (2004) Breathing adapted radiotherapy of breast cancer: reduction of cardiac and pulmonary doses using voluntary inspiration breath-hold. Radiother Oncol 72: 53-60.

10. Krauss DJ, Kestin LL, Raff G, Yan D, Wong J, Gentry R, et al. (2005) MRIbased volumetric assessment of cardiac anatomy and dose reduction via active breathing control during irradiation for left-sided breast cancer. Int $J$ Radiat Oncol 61: 1243-1250.

11. Korreman SS, Pedersen AN, Aarup LR, Nøttrup TJ, Specht L, et al. ()2006 Reduction of cardiac and pulmonary complication probabilities afte breathing adapted radiotherapy for breast cancer. Int J Radiat Oncol 65: 1375-1380.

12. Korreman SS, Pedersen AN, Nøttrup TJ, Specht L, Nyström H (2005) Breathing adapted radiotherapy for breast cancer: Comparison of free breathing gating with the breath-hold technique. Radiother Oncol 76: 311 318.

13. Nemoto K, Oguchi M, Nakajima M, Kozuka T, Nose T, et al. (2009) Cardiacsparing radiotherapy for the left breast cancer with deep breath-holding Jpn J Radiol 27: 259-263.

14. Stranzl H, Zurl B (2008) Postoperative Irradiation of Left-Sided Breas Cancer Patients and Cardiac Toxicity. Strahlentherapie und Onkol 184 354-358

15. Latty D, Stuart KE, Wang W, Ahern V (2015) Review of deep inspiration breath-hold techniques for the treatment of breast cancer. J Med Radiat Sci 62: 74-81.

16. Stranzl H, Zurl B, Langsenlehner T, Kapp KS (2009) Wide Tangential Fields Including the Internal Mammary Lymph Nodes in Patients with Left-Sided Breast Cancer. Strahlentherapie und Onkol 185: 155-160.

17. Borst GR, Sonke JJ, Den Hollander S, Betgen A, Remeijer P, et al. (2010) Clinical results of image-guided deep inspiration breath hold breas irradiation. Int J Radiat Oncol Biol Phys 78: 1345-1351

18. Vikström J, Hjelstuen MHB, Mjaaland I, Dybvik KI (2011) Cardiac and pulmonary dose reduction for tangentially irradiated breast cancer utilizing deep inspiration breath-hold with audio-visual guidance, without compromising target coverage. Acta Oncol 50: 42-50.

19. Johansen S, Vikström J, Hjelstuen MHB, Mjaaland I, Dybvik KI, et al. () Dose evaluation and risk estimation for secondary cancer in contralateral breast and a study of correlation between thorax shape and dose to organs at risk following tangentially breast irradiation during deep inspiration breath-hold and free breathing. Acta Oncol 50: 563-568.

20. Mclntosh A, Shoushtari AN, Benedict SH, Read PW, Wijesooriya K (2011) Quantifying the Reproducibility of Heart Position During Treatment and Corresponding Delivered Heart Dose in Voluntary Deep Inhalation Breath Hold for Left Breast Cancer Patients Treated With External Beam Radiotherapy. Int J Radiat Oncol 81: e569-e576.

21. Hjelstuen MHB, Mjaaland I, Vikström J, Dybvik KI (2012) Radiation during deep inspiration allows loco-regional treatment of left breast and axillarysupraclavicular- and internal mammary lymph nodes without compromising target coverage or dose restrictions to organs at risk. Acta Oncol 51: 333 344

22. Wang W, Purdie TG, Rahman M, Marshall A, Liu FF, etal. (2012) Rapid automated treatment planning process to select breast cancer patients for active breathing control to achieve cardiac dose reduction. Int J Radia Oncol Biol Phys 82: 386-393.

23. Hayden AJ, Rains M, Tiver K (2012) Deep inspiration breath hold technique reduces heart dose from radiotherapy for left-sided breast cancer. $\mathrm{J}$ Med Imaging Radiat Oncol 56: 464-472.
24. Nissen HD, Appelt AL (2013) Improved heart, lung and target dose with deep inspiration breath hold in a large clinical series of breast cancer patients. Radiother Oncol 106: 28-32.

25. Reardon KA, Read PW, Morris MM, Reardon MA, Geesey C, et al. (2013) A comparative analysis of $3 \mathrm{D}$ conformal deep inspiratory-breath hold and free-breathing intensity-modulated radiation therapy for left-sided breast cancer. Med Dosim 38: 190-195.

26. Swanson T, Grills IS, Ye H, Entwistle A, Teahan M, et al. (2013) Six-yea Experience Routinely Using Moderate Deep Inspiration Breath-hold for the Reduction of Cardiac Dose in Left-sided Breast Irradiation for Patients With Early-stage or Locally Advanced Breast Cancer. Am J Clin Oncol 36: 24-30.

27. Bruzzaniti V, Abate A, Pinnarò P, D'Andrea M, Infusino E, et al. (2013) Dosimetric and clinical advantages of deep inspiration breath-hold (DIBH) during radiotherapy of breast cancer. J Exp Clin Cancer Res 32: 88

28. Mast ME, van Kempen-Harteveld L, Heijenbrok MW, Kalidien Y, Rozema H, et al. (2013) Left-sided breast cancer radiotherapy with and without breathhold: Does IMRT reduce the cardiac dose even further? Radiother Oncol 108: 248-253.

29. Comsa D, Barnett E, Le K, Mohamoud G, Zaremski D, et al. (2014) Introduction of moderate deep inspiration breath hold for radiation therapy of left breast: Initial experience of a regional cancer center. Pract Radiat Oncol 4: 298-305.

30. Bolukbasi Y, Saglam Y, Selek U, Topkan E, Kataria A, Unal Z, et al. (2014) Reproducible deep-inspiration breath-hold irradiation with forward intensitymodulated radiotherapy for left-sided breast cancer significantly reduces cardiac radiation exposure compared to inverse intensity-modulated radiotherapy. Tumori 100: 169-178.

31. Osman SOS, Hol S, Poortmans PM, Essers M (2014) Volumetric modulated arc therapy and breath-hold in image-guided locoregional left-sided breast irradiation. Radiother Oncol 112: 17-22.

32. Rochet N, Drake JI, Harrington K, Wolfgang JA, Napolitano B, et al. (2015) Deep inspiration breath-hold technique in left-sided breast cancer radiation therapy: Evaluating cardiac contact distance as a predictor of cardiac exposure for patient selection. Pract Radiat Oncol 5: e127-e134.

33. Wong JW, Sharpe MB, Jaffray DA, Kini VR, Robertson JM, et al. (1999) The use of active breathing control $(A B C)$ to reduce margin for breathing motion. Int J Radiat Oncol Biol Phys 44: 911-919.

34. Faulkner K (2012) eviQ cancer treatments online - Uptake and usage in the radiation oncology community. J Med Imaging Radiat Oncol 56: 226-256.

35. Cancer Institute of NSW. EviQ Guidelines

36. Bartlett FR, Colgan RM, Donovan EM, Carr K, Landeg S, et al. (2014) Voluntary breath-hold technique for reducing heart dose in left breast radiotherapy. J Vis Exp 89: 51578.

37. Paszat LF, Mackillop WJ, Groome PA, Boyd C, Schulze K, et al. (1998) Mortality from myocardial infarction after adjuvant radiotherapy for breast cancer in the surveillance, epidemiology, and end-results cancer registries. J Clin Oncol 16: 2625-2631.

38. Giordano SH, Kuo Y-F, Freeman JL, Buchholz TA, Hortobagyi GN, et al. (2005) Risk of Cardiac Death After Adjuvant Radiotherapy for Breast Cancer. JNCl J Natl Cancer Inst. 97: 419-424.

39. Roychoudhuri R, Robinson D, Putcha V, Cuzick J, Darby S, et al (2007) Increased cardiovascular mortality more than fifteen years after radiotherapy for breast cancer: a population-based study. BMC Cancer 7: 9

40. Early Breast Cancer Trialists' Collaborative Group (EBCTCG) P, Darby S McGale P, Correa C, Taylor C, et al. (2011) Effect of radiotherapy after breast-conserving surgery on 10-year recurrence and 15-year breast cancer death: meta-analysis of individual patient data for 10,801 women in 17 randomised trials. Lancet (London, England) 378: 1707-1716.

41. Clarke M, Collins R, Darby S, Davies C, Elphinstone P, Evans V, et al. (2005) Effects of radiotherapy and of differences in the extent of surgery for early breast cancer on local recurrence and 15-year survival: an overview of the randomised trials. Lancet 366: 2087-2106

42. Muren LP, Maurstad G, Hafslund R, Anker G, Dahl O (2002) Cardiac and pulmonary doses and complication probabilities in standard and conformal tangential irradiation in conservative management of breast cancer. Radiother Oncol 62: 173-183

43. Bartlett FR, Colgan RM, Carr K, Donovan EM, McNair HA, et al. (2013) The UK HeartSpare Study: Randomised evaluation of voluntary deepinspiratory breath-hold in women undergoing breast radiotherapy. Radiother Oncol 108: 242-247.
Int J Gynecol Clin Pract

ISSN: 2394-4986
IJGCP, an open access journal

Volume 4. 2017. 133 
Citation: Parasuramar A, DeSmit A, Borg M (2017) Deep Inspiration Breath Hold Techniques in the Radiotherapeutic Management of Left-Sided Breast CancerActive Breathing Coordinator vs. Voluntary Breath Hold. Int J Gynecol Clin Pract 4: 133. doi: https://doi.org/10.15344/2394-4986/2017/133

Page 7 of 7

44. Zurl B, Stranzl H, Winkler P, Kapp KS (2010) Quantitative Assessment of Irradiated Lung Volume and Lung Mass in Breast Cancer Patients Treated with Tangential Fields in Combination with Deep Inspiration Breath Hold (DIBH). Strahlentherapie und Onkol 186: 157-162.

45. Taylor CW, Zhe W, Macaulay E, Jagsi R, Duane F, et al. (2015) Exposure of the heart in breast cancer radiation therapy: A systematic review of heart doses published during 2003 to 2013. Int J Radiat Oncol Biol Phys 93: 845-853.

46. Prosnitz RG, Hubbs JL, Evans ES, Zhou S-M, Yu X, Blazing MA, et al (2007) Prospective assessment of radiotherapy-associated cardiac toxicity in breast cancer patients: Analysis of data 3 to 6 years after treatment. Cancer 110: 1840-1850.

47. Mittauer KE, Deraniyagala R, Li JG, Lu B, Liu C, Samant SS, et al. (2015) Monitoring ABC-assisted deep inspiration breath hold for left-sided breas radiotherapy with an optical tracking system. Med Phys 42: 134-143. 